\title{
An assessment of dapsone self-administration in Gudiyatham Taluk. How should urinary dapsone / creatinine ratios be used?
}

\author{
C J CATES \\ University of Oxford Medical School \\ Received for publication 4 February 1980
}

Summary The self-administration of daily doses of $50 \mathrm{mg}$ and $100 \mathrm{mg}$ dapsone by leprosy patients in Gudiyatham Taluk, South India, was monitored by measuring urinary dapsone/creatinine ratios in out-patients compared with a group of in-patient controls on supervised doses of dapsone. A new method is described to analyse the results of such a survey; if used widely this would allow comparison between the results of surveys in different areas. Overall $37 \%$ of the 189 out-patients tested were judged to be taking dapsone regularly. The results were the same whether patients were tested at clinics or at surprise home visits. The implications of these results are discussed with reference to leprosy control schemes and to further studies of this kind.

\section{Introduction}

Dapsone is still the most important drug used in the treatment of leprosy, it is cheap and effectively controls the disease if patients take the tablets regularly. In South India, patients with leprosy are prescribed dapsone on a daily basis, a $25 \mathrm{mg}$ tablet for children, a $50 \mathrm{mg}$ tablet for adults unless they have Lepromatous leprosy, when a $100 \mathrm{mg}$ tablet is prescribed.

In Gudiyatham Taluk in South India, which has a population of 420,000 , there are over 8,000 patients who suffer from leprosy: they live at home in villages or small towns, and attend monthly clinics located within $5 \mathrm{~km}$ of their homes. Initially patients attend a clinic each month to receive their supply of dapsone tablets, but later they come four times a year and receive 3 months' supply of dapsone. In order to encourage regular attendance, Paramedical Workers visit patients on the day before they should come to a clinic, and on average $75 \%$ of patients then attend as requested.

I set out to find out how many of these patients, who came to clinics and collected their dapsone tablets, actually ingested the tablets when they went home. The patients are expected to take daily tablets for at least five years and it would not be surprising if compliance was low. Studies in other parts of the 
world using urinary dapsone/creatinine ratios to assess compliance, have indicated that only about a half of patients take their tablets regularly, ${ }^{1-3}$ but a study in 1976 from Karigiri Hospital in Gudiyatham Taluk indicated that about three-quarters of patients were taking their dapsone regularly. ${ }^{4}$

\section{Sampling methods}

The out-patient clinics at Gudiyatham Taluk are divided into three areas: Area I is within $20 \mathrm{~km}$ of the hospital, Area II within $80 \mathrm{~km}$ and Area III within $150 \mathrm{~km}$. Ten clinics were randomly chosen for the study, four from Area I, two from Area II and four from Area III. Urine samples were obtained from a total of 73 patients at their visit to their out-patient clinic. Urine samples were also collected from 116 patients from the same clinics by means of surprise visits to their homes. These were carried out early in the morning by the author and a Paramedical Worker, and were at least a week before the next clinic visit was due. All patients were randomly selected on the morning of the visit to rule out any special attention by Paramedical Workers to the patients involved in the study.

Information was collected for each patient about age, disabilities, date of registration, mode of detection, attendance at clinics in the previous year, type of leprosy and the distance they had to come to the clinic.

\section{Urine tests to estimate compliance}

The urinary ratios of the concentration of dapsone plus its diazotisable metabolites to creatinine (D/C ratios) were measured by the method described by Ellard et $a l^{5}$ using a Unicam SP 600 spectrophotometer provided by Karigiri Hospital and standards provided by Dr Ellard. 'Blank' D/C ratios were determined by analysing urine samples from 22 healthy members of the hospital staff at Karigiri who were not taking dapsone. Significant blank ratios are due to the presence of natural diazotisable compounds in the urine.

In order to assess the $\mathrm{D} / \mathrm{C}$ ratio in fully supervised patients urine samples were collected from 36 in-patients at Karigiri Hospital. Twentyfour patients received $50 \mathrm{mg}$ dapsone daily and 12 patients received $100 \mathrm{mg}$ dapsone daily given in the morning by the nurses. All of these patients provided urine samples $24 \mathrm{~h}$ after taking a dose of dapsone, and some provided a further sample $6 \mathrm{~h}$ after taking the next dose.

\section{Results}

CONTROLS

The mean 'blank' $\mathrm{D} / \mathrm{C}$ ratio for the 22 staff members not taking dapsone was $7.5 \mu \mathrm{g} / \mathrm{mg}$, with individual results ranging from 1.1 to $16.0 \mu \mathrm{g} / \mathrm{mg}$. In the fully 
supervised patients taking $50 \mathrm{mg}$ dapsone daily the mean D/C ratio at $24 \mathrm{~h}$ was $48.9 \mu \mathrm{g} / \mathrm{mg}$ (standard deviation $11.2 \mu \mathrm{g} / \mathrm{mg}$ ), and in those taking $100 \mathrm{mg}$ dapsone daily it was $83.8 \mu \mathrm{g} / \mathrm{mg}$ (SD $28.2 \mu \mathrm{g} / \mathrm{mg}$ ). The distribution of individual control and out-patient $\mathrm{D} / \mathrm{C}$ ratios is shown in Fig. 1.

\section{Development of criteria for assessing compliance}

The D/C ratios of the urine samples collected from the controls were analysed in such a way as to enable criteria to be developed to judge whether or not it was likely that out-patients had ingested their last dose of dapsone within the previous $24 \mathrm{~h}$ prior to the collection of the urine sample. For this purpose I assumed that dapsone is fully absorbed within $6 \mathrm{~h}$ and that the urinary rate of elimination of dapsone and its diazotisable metabolites thereafter falls exponentially. ${ }^{6}$ The half-life for the elimination of dapsone and its metabolites could therefore be calculated from the mean $6 \mathrm{~h}$ and $24 \mathrm{~h} \mathrm{D} / \mathrm{C}$ ratios of the supervised controls after subtracting the mean blank $\mathrm{D} / \mathrm{C}$ ratio $(7.5 \mu \mathrm{g} / \mathrm{mg})$ since this does not change with time. This yielded a mean half-life of $25 \mathrm{~h}$ which is similar to that of $24 \mathrm{~h}$ found by Ellard. ${ }^{6}$ This half-life was then employed to estimate the scatter of $\mathrm{D} / \mathrm{C}$ ratios that might have been expected at $48 \mathrm{~h}$. The observed $24 \mathrm{~h} \mathrm{D} / \mathrm{C}$ ratios of the controls after supervised daily doses of 50 and $100 \mathrm{mg}$ dapsone together with the calculated $48 \mathrm{~h}$ ratios are illustrated in Fig. 2. The $24 \mathrm{~h}$ and $48 \mathrm{~h}$ distributions overlapped and the horizontal lines shown in Fig. 2 represent the $\mathrm{D} / \mathrm{C}$ ratios that would imply that there was an equal chance that such a patient had ingested their last dapsone dose either $24 \mathrm{~h}$ or $48 \mathrm{~h}$ previously I therefore classified out-patients as 'regular' in self-administering dapsone if their $\mathrm{D} / \mathrm{C}$ ratios exceeded these cut-off points $(37.5$ and $60 \mu \mathrm{g} / \mathrm{mg}$ respectively for dosage with 50 or $100 \mathrm{mg}$ dapsone daily), and 'irregular' if they fell below such values yet exceeded the highest $\mathrm{D} / \mathrm{C}$ ratio for the untreated controls $(16 \mu \mathrm{g} / \mathrm{mg})$. Out-patients with $\mathrm{D} / \mathrm{C}$ ratios of less than $16 \mu \mathrm{g} / \mathrm{mg}$ were classified as 'grossly irregular'. The distributions of $\mathrm{D} / \mathrm{C}$ ratios illustrated in Figs. 1 and 2 indicate that out-patients classified as 'regular' had probably taken a dose of dapsone with the previous $24 \mathrm{~h}$, that those judged to be 'irregular' had probably omitted to take a dose of dapsone the previous day but had in all probability self-administered some treatment within the $48 \mathrm{~h}$ preceeding collection of the urine sample. By contrast 'grossly irregular' patients had probably taken no drug in the previous 3 or 4 days.

\section{OUT-PATIENTS}

Tables 1 and 2 summarize this classification of the out-patients and include estimates of the average time since each group of patients last ingested a dapsone tablet. These times were estimated by dividing the mean $\mathrm{D} / \mathrm{C}$ ratio of the out-patients by that of the controls after correcting for the blank and 

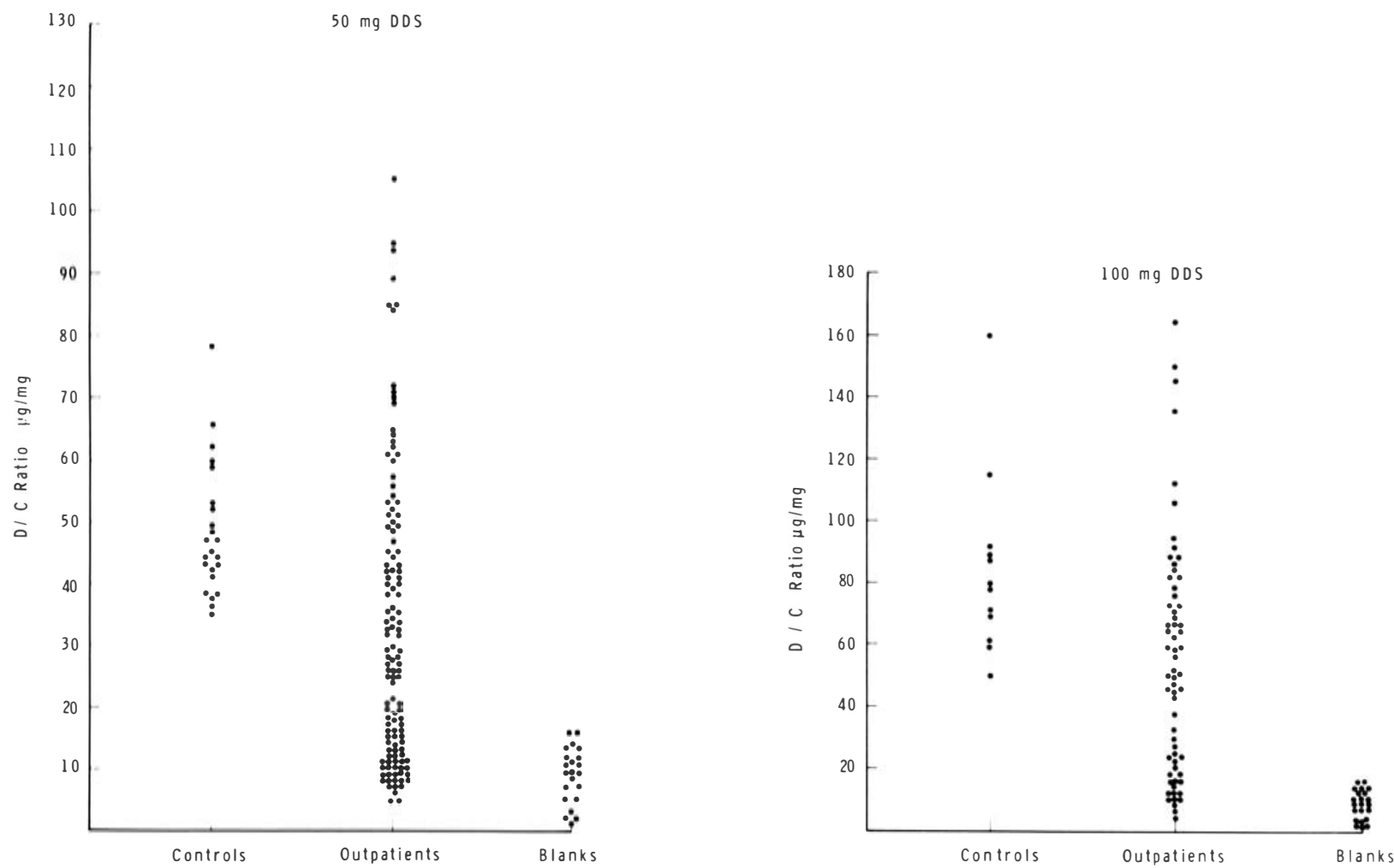

Figure 1. Urinary $\mathrm{D} / \mathrm{C}$ ratios in controls and out-patients taking $50 \mathrm{mg}$ and $100 \mathrm{mg}$ dapsone daily. 


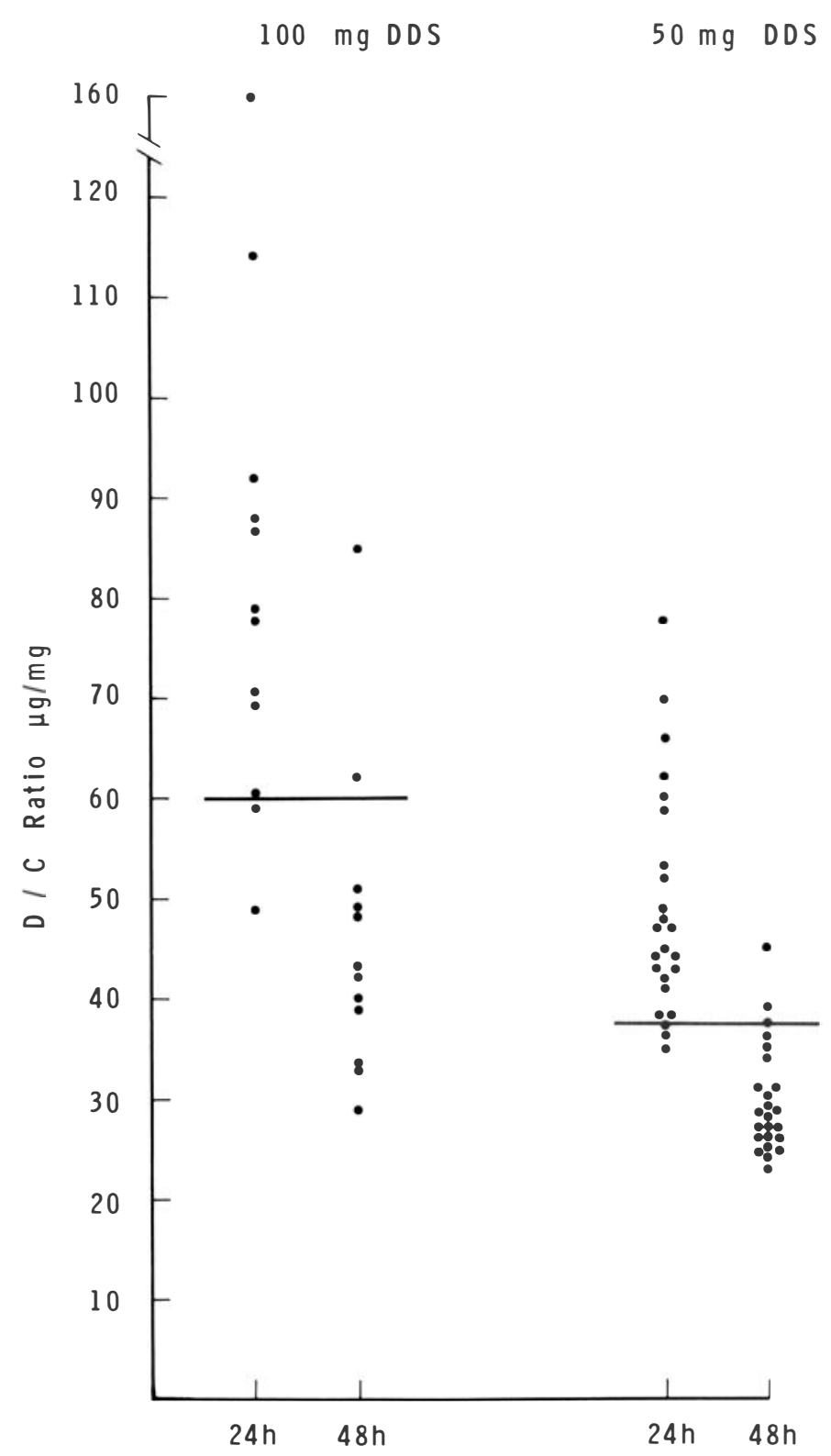

Figure 2. Urinary $\mathrm{D} / \mathrm{C}$ ratios at $24 \mathrm{~h}$ and $48 \mathrm{~h}$ in controls on $50 \mathrm{mg}$ and $100 \mathrm{mg}$ dapsone.

utilizing the calculated half-life of $25 \mathrm{~h}$ for the assumed exponential fall in the rate of elimination of dapsone plus its diazotisable metabolites.

Of 189 out-patients tested at clinics and at home, 71 were classified as 'regular', 58 as 'irregular' and 60 as 'grossly irregular'. The overall compliance was similar whether measured at clinics or at home-visits between clinics. Of 15 
Table 1. Comparison of $\mathrm{D} / \mathrm{C}$ ratios of urine samples from supervised controls and out-patients on $50 \mathrm{mg}$ DDS daily

\begin{tabular}{|c|c|c|c|c|c|}
\hline & Number & $\begin{array}{c}\text { Mean } \mathrm{D} / \mathrm{C} \text { ratio } \\
\mu \mathrm{g} / \mathrm{mg}\end{array}$ & $\begin{array}{l}\text { Range of } \mathrm{D} / \mathrm{C} \text { ratios } \\
\mu \mathrm{g} / \mathrm{mg}\end{array}$ & $\frac{\text { Out-patient mean }}{\text { control mean }}$ & $\begin{array}{l}\text { Hours since* } \\
\text { last DDS dose }\end{array}$ \\
\hline Controls & 24 & 48.9 & $35.3-78.8$ & - & 24 \\
\hline $\begin{array}{l}\text { 'Regular' } \\
\text { out-patients }\end{array}$ & $45(36 \%)$ & 59.3 & $38.2-124$ & 1.25 & 16 \\
\hline $\begin{array}{l}\text { ‘Irregular’ } \\
\text { out-patients }\end{array}$ & $34(27 \%)$ & 27.6 & $16.4-37.3$ & 0.49 & 50 \\
\hline $\begin{array}{l}\text { 'Grossly irregular' } \\
\text { out-patients }\end{array}$ & $46(37 \%)$ & 9.8 & $3.2-16.0$ & 0.06 & 128 \\
\hline Total out-patients & 125 & 32.5 & $3.2-124$ & 0.6 & 42 \\
\hline
\end{tabular}

${ }^{*}$ See text. 
Table 2. Comparison of $\mathrm{D} / \mathrm{C}$ ratios of urine samples from supervised controls and out-patients on 100 mg DDS daily

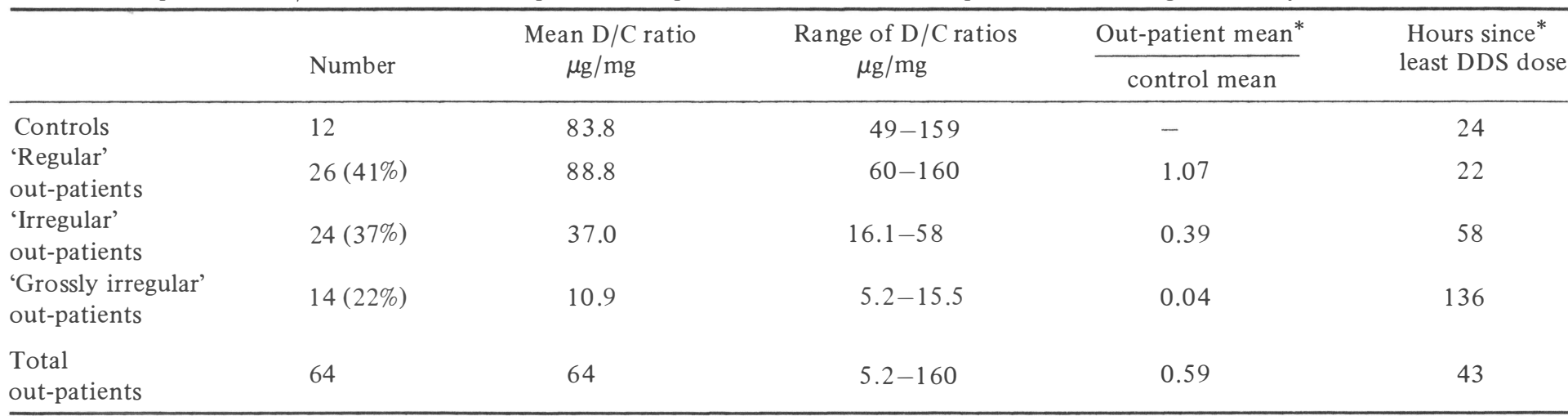

Hours since*

${ }^{*}$ See text. 
patients tested on both occasions, the compliance of 7 was the same both times, in 4 it was worse at home and in 4 it was better. Thus compliance was not significantly influenced by the day on which the sample was collected.

Considerable variation was found in the compliance of patients attending different clinics, from the worst where only 1 patient in 11 was regular to the best where 10 out of the 16 patients were regular. These sample sizes were however too small for the differences to be statistically significant. Compliance was not related to the distance of the clinic from the hospital, nor was it related to the attendance rate at the clinic. As far as individual patients were concerned, missing clinics in the previous year did not mean that they ingested fewer tablets when they did collect them from the clinic. Fiftyone per cent of the patients whose homes were between 2 and $5 \mathrm{~km}$ from the site of the clinic were classified as 'regular' in contrast to only 30\% of those living under $2 \mathrm{~km}$ from the clinic ( $p=0.01$ using chi-square test). Eleven per cent of patients who were found to have leprosy during general surveys of the population were classified as 'regular' compared with $39 \%$ of those who presented voluntarily at clinics and $53 \%$ of those found as contacts of known patients $(p=0.02)$. Twentyeight per cent of tuberculoid patients were 'regular' compared with $42 \%$ 'regular' in other groups $(p=0.05)$.

The disability of the patients did not affect their compliance, and patients who had only been registered for one year or less were no better at taking their tablets than those who had been registered for longer periods.

\section{Discussion}

While measuring the dapsone concentration in acidified urine samples, I noted that on addition of the nitrite reagent a pink colouration developed in about a fifth of the samples. Hence if one measured the OD immediately before the addition of $\mathrm{N}$-I-naphthyl-ethylene-diamine-dihydrochloride, rather than before the addition of nitrite as suggested in the original method of Ellard, the blank $\mathrm{D} / \mathrm{C}$ ratio could be reduced in such samples by up to $75 \%$.

An attempt was made to assess the compliance of children prescribed $25 \mathrm{mg}$ dapsone daily, but it was impossible to interpret the results because of the wide range of $\mathrm{D} / \mathrm{C}$ ratios in the controls $(12-90 \mu \mathrm{g} / \mathrm{mg})$. Although a wide range in creatinine excretion might be expected due to the difference in the weight of the children, the individual $\mathrm{D} / \mathrm{C}$ ratios did not correlate with the size of the children. As there were few children in the hospital, out-patient children were used as controls and the variability of results may have been due to inadequate supervision.

The importance of good control results cannot be overemphasized, and in future studies of this kind it would be of value to collect urine samples $24 \mathrm{~h}$ and $48 \mathrm{~h}$ after a supervised course of dapsone in at least 20 patients. The 
distribution of the $24 \mathrm{~h}$ and $48 \mathrm{~h}$ ratios can then be used to assess the best criteria for discriminating between 'regular' and 'irregular' patients.

This study has shown that urine samples taken at clinics are representative of the level of compliance of the population; as long as the tests are unexpected at clinics, it is not necessary to carry out surprise home visits when assessing the compliance of the population. However this should be reassessed at a future date, since encouragement by paramedical workers might improve tablet-taking just before the clinics without altering compliance in the period between clinics.

The most worrying group in the study were the 12 lepromatous patients who appeared to be 'grossly irregular' in self-administrating their prescribed dapsone treatment. These patients could become infectious again if they do not take dapsone, and also have a greater danger of developing dapsone-resistant disease. About 20 dapsone-resistant cases have already been detected at Karigiri. These 'grossly irregular' lepromatous patients need special encouragement to improve their compliance. Thus they might be hospitalized for a short period (3-4 days) so that a series of consecutive daily doses of dapsone could be given under supervision. A urine sample would then be obtained prior to the final supervised dose to provide a control $\mathrm{D} / \mathrm{C}$ ratio for comparing results from subsequent urine samples obtained during routine out-patient treatment.

The results of this study emphasize the important role that paramedical workers should play to inspire patients not only to attend clinics regularly but also to take their dapsone each day.

\section{Acknowledgements}

I am most grateful to Dr Ellard (Royal Postgraduate Medical School, London) and Professor Vessey (Department of Social and Community Medicine, Oxford) for their assistance in this study, and to Lepra who provided a generous grant towards the cost of my visit at Karigiri. I would also like to thank all those at Karigiri who made it possible for me to do this study.

\section{References}

1 Low SJM, Pearson JMH. Do leprosy patients take dapsone regularly? Lepr Rev, 1974, $45,218-23$.

2 Ellard GA, Gammon PT, Harris JM. The application of urine tests to monitor the regularity of dapsone self-administration. Lepr Rev, 1974, 45, 225-34.

3 Huikeshoven HCJ, Honhoff C, Van Eys GJJM, Anten JGF, Mayer JMA, Van Helden HPT. Weekly self-medication of leprosy patients monitored by DDS/Creatinine ratio in urine. LeprRev, 1976, 47, 201-9.

4 Jesudasan K, George B, Chacko CJG, Taylor PM, Kurian PV, Job CK. An evaluation of the self-administration of DDS in Gudiyatham Taluk. Lepr India, 1976, 48, 668-76. 
5 Ellard GA, Gammon PT, Helmy HS, Rees RJW. Urine tests to monitor the selfadministration of dapsone by leprosy patients. Amer J Trop Med Hyg, 1974, 23, 464-70.

6 Ellard GA. Profile of urinary dapsone/creatinine ratios after oral dosage with dapsone. Lepr Rev, 1980, 51, 229-36. 